\title{
The Role of Intrinsic Goal Orientation on Medical and Allied Health Students' Deep Learning Approach
}

\author{
Flemmings Fishani Ngwira \\ Department of Language and Communication \\ University of Malawi, The Polytechnic \\ Blantyre, Malawi \\ fishaningwira@gmail.com \\ Alemayehu Belay Emagnaw \\ Department of School and Counselling Psychology \\ Woldia University \\ Woldia, Ethiopia
}

\author{
Patmawaty Taibe \\ Department of Psychology \\ Bosowa University \\ Makassar, Indonesia
}

\author{
Hanna Yeshinegus Adamseged \\ School of Psychology \\ Central China Normal University \\ Wuhan, China
}

\begin{abstract}
Medical institutions have an exceptional responsibility to train health providers to become versatile in their own fields, trying to foster and stimulate life-long skills such as problem solving and critical thinking. Research on academic self-regulation suggests that students' intrinsic goal orientation and deep approach to learning enhance students' learning. The primary goal of this study was to investigate the role intrinsic goal orientation plays on students' deep learning approach. A sample of 205 first year students (121 males and 84 females) from College of Medicine in Malawi responded to a questionnaire assessing their intrinsic goal orientation and deep learning strategy approach. Data were analyzed using IBM SPSS Statistics, version 20. Linear regression results indicate that intrinsic goal orientation positively predicted both deep and meta-cognitive learning strategies as components of deep learning approach construct. Male students had higher levels of intrinsic goal orientation than their female counterparts. There were no significant differences among students from different programs of study on intrinsic goal orientation, deep and meta-cognitive learning strategies. The results suggest that intrinsic goal orientation has an important impact on medical and allied health students' deep learning approach. Possible implications of the results and recommendations for future research are discussed.
\end{abstract}

Keywords-intrinsic goal orientation, deep learning approach, deep learning strategies, meta-cognitive learning strategies

\section{INTRODUCTION}

Medical institutions have a unique obligation to train medical and other health professionals fit for the practice [1]. In medical profession, issues of competencies and outcomes are important aspects in performance. However, teaching medicine and allied health courses has faced a number of challenges recently. As Tembo and Ngwira [2] note, one of the challenges has been the overall reduction of contact hours for basic medical science subjects. This reduction of contact hours leads to yet another challenge of imparting a large amount of knowledge within a limited period. As Samarakoon et al. [3] argue, if not taken carefully, this challenge would affect the way students retain, remember and effectively interpret the materials learnt. In order to make the teaching meaningful, there has been a shift in the teaching approach, especially in medical field, from the traditional teachercentered to student-centered where the use of interactive and problem-based learning is preferred [3]-[5]. Most medical institutions have adopted the student-centered teaching approach [3,6], and College of Medicine (CoM) is also moving towards incorporating the approach, especially the Problem-Based Learning [2].

Problem-based learning (PBL) has been defined as the learning that results from the process of working towards the understanding of a resolution of a problem [7]. This teaching approach allows students to acquire case-specific problemsolving expertise and the ability to apply their own previous knowledge and gain new information while solving these problems using critical thinking skills [4]. In PBL, therefore, students are encouraged to take responsibility for their own learning process [8]; they become active contributors in their own learning. Research reveals that the PBL's teaching method naturally influences students' approach to learning by fostering meaningful, comprehensive, and deep learning [3][5]. Consequently, PBL has been a useful and increasingly applied educational method because of its benefits $[6,4]$. Using PBL implies that students need to be motivated enough to take up the responsibility of monitoring their own learning, and it is vital that medical and allied students become prepared for this new teaching approach as early as first year. Therefore, for this study, it was important to investigate students' motivation to learning and the learning approach they adopt, as early as first year.

\section{A. Motivational goal orientation}

As medical education is becoming more self-directed, students need to be more organized and one way to achieve this is to acquire higher levels of self-motivation. Motivation can be defined as an internal state that arouses, directs, and maintains behavior [9]. From a cognitive perspective, Pintrich and Schunk [10] define motivation as "the process whereby a goal-directed activity is instigated and sustained" (p. 4). From the latter definition, we can conclude that to know what motivates students; one has to observe their behaviors in terms of the goals they adopt in their learning process. Goals provide students with the direction and a purpose to engage in a school-related activity [10]. Goal orientation, therefore, is an integral part of motivation; it has become one of the most applicable, and predominant theories used to understand students' academic motivation [11]. Thus, motivational goal orientation theory provides a viable framework to the current study in an attempt to investigate the role intrinsic goal 
orientation plays on deep learning approach among medical and allied health students.

Goal orientation, especially in education can be defined as a set of behavioral intentions that determine how students approach and participate in learning activities [9]. These intentions are students' beliefs concerning their goals that help in explaining why attaining that goal is important to them. For instance, when a student wants to obtain an $\mathrm{A}^{*}$ grade in class, is it because he/she wants to be the highest in class or because he/she wants to master the course content well? Answers to such questions have a great deal to do with students' motivation and have consequences for their academic and professional accomplishment. Responses to these questions lead us to the dichotomy of goal orientation; the intrinsic and extrinsic goal orientation. The expectancy-value model of selfregulated learning posits that the primary goals students possess for participating in an activity are either intrinsically or extrinsically motivated [12,13]. According to the model, students who adopt an intrinsic goal orientation to learning usually focus on internal factors such as mastering and understanding the materials they study [14]. Conversely, students who adopt an extrinsic goal orientation approach learning activities with a focus on external factors such as grades, rewards, and approval from others [12,14].

Based on the intrinsic and extrinsic goal orientation, research on motivational goal orientation has suggested that there are two general goal orientations students adopt towards their learning: a mastery/learning goal orientation and a performance goal orientation. Murphy and Alexander [15] define mastery goal orientation as "a desire to develop competence and increase knowledge and understanding through effortful learning"; and performance goal orientation as "a desire to gain favorable judgments of one's competence" (p. 28). Expressing it differently, mastery goal orientation is when the student is focused on mastery and learning of the material and a performance goal orientation is when the student is focused on demonstrating his/her ability and performance in relation to other students [16]. In this regard, students who are intrinsically motivated adopt a mastery goal orientation and those who are extrinsically motivated adopt a performance goal orientation.

A number of studies have attested the importance of intrinsic goal orientation on mastery learning approach; it is associated with high-quality learning outcomes. Students who are intrinsically oriented, and who focus on learning and mastery of the materials tend to place high intrinsic value on learning; are inclined to use deep information processing strategies, are self-efficacious and self-regulated; and attribute their success or failure to effort and strategy use $[9,16]$. McCollum and Kajs [9] continue to report that intrinsically oriented students tend to pursue challenging tasks, spend a great deal of time on the tasks given, have positive attitude toward class and enjoy lectures. These are the most desirable attributes students need to demonstrate for learning to be meaningful to them. Consequently, intrinsic goal orientation has extensively been regarded as vital predictors of academic performance $[9,17]$. Research on intrinsic motivation has also indicated that intrinsic goal orientation enhances productivity in adults in their working world [17].
On the other hand, research indicates that extrinsic goal orientation is associated with negative learning outcomes because students' characteristics are not affiliated with academic success [9]. Since extrinsic goal orientation is linked with the performance learning approach; the principal concern of performance-oriented students is to outperform others $[9,16]$. This kind of learning approach where students primarily focus on out-performing others would not give chance to learners to appreciate the intrinsic value of learning. Literature indicates that students who are extrinsically oriented, and who focus on performance often use minimal effort to outperform their colleagues, and this lack of effort further leads to usage of shallow information processing strategies such as rote memorization. Students adopting this kind of learning approach usually have negative attitudes toward class, and attribute their success or failure to fixed ability or task difficulty rather than effort $[9,16]$. When performance-learning approach is further split into performance-approach and performance-avoidance dichotomy, where students with the former approach seek to gain positive judgements of their competence in relation to others, and the students with the latter approach seek to avoid negative judgments of their performance, research indicates that performance-approach goals seem to be associated with the positive outcomes [9]. However, as other studies reveal, the positive outcomes associated with performance-approach goals are usually found only when paired with mastery goals [12] since students can adopt different combinations of intrinsic and extrinsic goals $[11,12,18]$. These findings further attest intrinsic goal orientation to be a necessary part of the equation.

\section{B. Students' approaches to learning}

Based on the work established by Marton and Saljo $[19,20]$, Briggs developed a model of approaches to learning [21]. The model posits that there are two types of approaches to learning students employ: deep and surface approaches. The model explains students' different intentions when approaching an academic task; some aim to understand the meaning while others aim to be able to reproduce when asked. In their research, Briggs and Tang [21] found that students with intentions to understand the meaning would relate the information to prior knowledge, properly structure ideas, and critically evaluate knowledge, and this approach to learning was referred to as the deep approach. On the other hand, students who aimed to be able to reproduce when asked were found to commit text to memory, and this approach to learning was referred to as the surface approach. Research on approaches to learning indicates that these approaches are influenced by several factors such as the learning environment, students' perceptions of the environment and student characteristics, for instance, their prior knowledge on the topic [21]-[23].

Deep learning approach is not a new concept in higher education; it has drawn more attention currently as educational institutions try to tap their students' full learning potential. Briggs and Tang [21] defines deep approach as an approach whereby students meaningfully engage with the course content and treat it as something worthy time spending and understanding. As a result of treating and engaging with the 
content material meaningfully, students use appropriate higher cognitive activities needed to learn the material. The learning approach model further relates deep learning approach to the motivations and the students' intrinsic desires [21,24]. This entails that students focus their attention on the underlying meanings and the successful applications of the content learnt when they feel the need to know. Empirically, research reveals that deep learning approach has been associated with highquality academic outcomes; students who use such an approach tend to retain, integrate and transfer information learnt at a higher rate, thereby earning higher grades [21]-[25]. Additionally, deep learning approach has also been associated with an enjoyable learning experience [25], which enhances motivation, facilitates learning and increases academic performance [1].

On the other hand, surface learning approach is defined as an approach whereby a student learns only enough to just pass assessment and fulfil the minimum requirements of the learning program [21]. According to the Brigg's model of learning approach [21], surface learning approach is mostly characterized by the memorization of facts as a substitute for understanding. Research reveals that students using surface learning approach focus on the substance of information and emphasize rote learning and memorization techniques; the goal of studying for an exam is to avoid failure, instead of grasping key concepts $[5,24,25,26]$. Such students are mostly influenced by assessment requirements [26]. Surface learning approach has been associated with negative academic outcomes especially when students tend to retain the materials for a longer period of time, integrate and transfer information and apply the content in different situations [24,25].

Since students' approaches to learning are influenced by two main factors: students' orientation to studying and the context of learning within individual courses [21,22], it is certain that students may adopt both deep and surface approaches in different situations in their studies. Although students may use different approaches at different points, Laird et al. [25] argue that the general tendency is to adopt a particular approach and stick with it. This entails that, for instance, although students who adopts deep learning approach may sometimes use rote memory to learn some facts, their main focus still remains on the underlying meaning of the information. Therefore, while clinging to their particular learning approach, students are bound to change their learning approaches depending on different situations. Since the main focus of most medical and allied health courses is on competencies and the ability to apply the theoretical concepts to professional contexts [27], a deep approach to learning remains a necessary part of their learning.

\section{Intrinsic goal orientation and deep learning approach}

The motivational goal orientation has an impact on how students approach learning. For instance, research indicates that intrinsic goal orientation is associated with deep information processing strategies while extrinsic goal orientation is associated with shallow information processing strategies $[9,16]$. Looking at the relationships between goal orientations and the learning approaches, and the effects of each dichotomy on students' learning and outcomes, the current study aimed at analysis intrinsic (not extrinsic) goal orientation and deep (not surface) learning approaches among first year College of Medicine students in Malawi. Since goal orientation and approaches to learning are influenced by several factors such as a particular discipline (e.g. hard science), teaching methods, students' perceptions of the teaching context and student characteristics [5,22,27], the current study wanted to test the assumptions of goal orientation and approaches to learning models on a different setting, Malawi, within the context of learning basic medical sciences. Literature indicates that surface learning approach is adopted by many medical and allied students as the major learning strategy to cope with their school work [27]-[29]. Surprisingly, most empirical studies do not appear to examine the link, which is there between intrinsic goal orientation and deep learning approach in the context of medicine.

The principal aim of this study therefore, was to investigate the role of intrinsic goal orientation on students' deep learning approach. Specific objectives were formulated to particularly 1) examine the relationship between intrinsic goal orientation and deep learning approach, and 2) investigate the extent at which medical and allied health undergraduate students demonstrate levels of intrinsic goal orientation and deep learning approach. Based on the literature on the two main constructs of the present study, it was hypothesized that 1) there would be a positive link between intrinsic goal orientation and deep learning approach, and 2) there would be differences between the two genders and among the four programs of study. In particular, male students would demonstrate high levels of both intrinsic goal orientation and deep learning approach.

\section{METHODS AND MATERIALS}

\section{A. Study design}

The current study was a survey research design using quantitative methods of data collection and analysis for a cross-sectional data. The survey aimed at investigating the role of students' intrinsic goal orientation on their deep learning approaches. Part of a predesigned and pre-tested survey was used to collect the data. No personal information that would identify individual participants was taken. Data was collected from college students at the end of their first professional year.

\section{B. Sample population}

The respondents of the current study were the 2015-2016 first year medical and allied health students aged between 18 and 22, enrolled at College of Medicine, a constituent college of the University of Malawi $(n=222)$. The students have different economic, cultural, and social backgrounds; the college enrolls students from every corner of the country, both government and self-sponsored. Each year, the college enrolls students into a one year foundation program (foundation year), as a preparatory training for their medical career. After a year, they become enrolled into their first professional year as medical and allied students (second-year at college), split into four different programs: Bachelor of Medicine Bachelor of Surgery (MBBS), Bachelor of Pharmacy (PHARM), Bachelor of Physiotherapy (PHYSIO), and Bachelor of Medical Laboratory Sciences (MLS). For the purpose of this study, all 
enrolled first-year students (second-year at college) were invited to participate in the study; there were no exclusion criteria.

\section{Procedure}

Since the current study involved human subjects as participants, it had to conform to some ethical principles to protect the life, privacy and confidentiality of participants. First, an institutional review board, College of Medicine Research Ethics Committee (COMREC) approved the research protocol. Second, the investigation was made anonymous, and finally, informed written consents were obtained from the participants themselves. Surveys assessing students' intrinsic goal orientation and deep learning approach with respect to their respective major courses were given to the participants in their classrooms. Participants were reminded of anonymity and confidentiality, and were told to complete the surveys at their own free time and return filled questionnaires to the dean of students' secretary's office before the end of business the following day.

\section{Instrumentation}

\section{Motivated Strategies for Learning Questionnaire (MSLQ)}

Part of the Pintrich et al.'s [30] Motivated Strategies for Learning Questionnaire (MSLQ) was used to measure the study concepts in their respective major courses: Introduction to Medical Laboratory Science for MLS, Anatomy for MBBS, Introduction to Physiotherapy for PHYSIO, and Introduction to Pharmacy for PHARM. Two separate sub-scales of the MSLQ were used to assess students' intrinsic goal orientation and deep learning approach. Participants responded to four questions assessing their intrinsic goal orientation with the coefficient alpha level of .74. Two dimensions of the cognitive and metacognitive sub-scale measured deep learning approach: deep learning strategies and meta-cognitive learning strategies. Participants responded to 15 items assessing their deep learning strategies: six items for elaboration $(\alpha=.76)$, four items for organization $(\alpha=.64)$, and five for critical thinking $(\alpha=80)$; and 12 items assessing their meta-cognitive learning strategies $(\alpha=.79)$. The questionnaire therefore, consisted of 31 items, scored on a 5-point Likert-type scale, ranging from 1 (not at all true of me) to 5 (very true of me). Sample items include: intrinsic goal orientation, "In a class like this, I prefer course material that really challenges me so I can learn new things"; deep strategies: elaboration, "When reading for this class, I try to relate the material to what I already know"; organization, "I make simple charts, diagrams or tables to help me organize course material"; critical thinking, "I often find myself questioning things I hear or read in this course to decide if I find them convincing"; meta-cognitive strategies, "I ask myself questions to make sure I understand the material I have been studying in this class".

\section{E. Data Analysis}

Statistical data analyses were done using IBM® SPSS $®$ statistics version 20. The survey items were first checked for normality and screened for accuracy and missing values.
Reliability analyses were also done to check for the instrument's reliability. Following the reliability tests, Pearson correlations were calculated to establish the relationship between variables tested in the study. Descriptive statistics for all the tested variables were realized and tabulated from raw data. A simple linear regression $(p<.05)$ was used to find out if students' intrinsic goal orientation predicted deep learning approach. To test if there were significant differences in intrinsic goal orientation and deep learning approach between male and female participants, independent samples $t$-test was used $(p<.05)$. Finally, one-way analysis of variance (ANOVA) was used to check for disparities of intrinsic goal orientation and deep learning approach experiences among four study programs of MBBS, PHARM, MLS, and PHYSIO ( $p<.05)$.

\section{RESULTS}

A total number of 205 students (92\%) of the target group participated in the study and completed the survey. According to their programs of study, 66 students (38 males and 28 females) came from MLS, 51 students (31 males and 19 females) from MBBS, 44 students (24 males and 20 females) from PHYSIO, and 44 students (26 males and 18 females) from PHARM. In total, the male-to-female ratio of the participants was 121 male students to 84 female students representing a $59 \%$ to $41 \%$ respectively. The reliabilities of the subscales from this survey were also computed; Cronbach alpha for intrinsic goal orientation was .59, for deep learning strategies was .88, and for meta-cognitive learning strategies was .78.

\section{A. Descriptive statistics and Pearson correlation statistics}

Table 1 presents descriptive results and the Pearson correlation analysis, for all the study variables. Correlation results show that there were significant positive relationships among the variables tested. A rather strong correlation can be observed between deep learning approach variables: deep strategy/meta-cognitive strategies. The strong relationship suggests shared variability between these concepts, and it proves the fact that they are both measuring one construct: deep learning approach. However, mild relationships can be observed between deep learning approach variables and intrinsic goal orientation: deep strategy/intrinsic goal orientation and meta-cognitive/intrinsic goal orientation. This suggests that the constructs are distinct.

TABLE 1. DESCRIPTIVE STATISTICS AND PEARSON CORRELATION ANALYSIS $(n=205)$

\begin{tabular}{|c|c|c|c|c|c|c|}
\hline \multicolumn{2}{|c|}{ Variable } & Mean & SD & 1 & 2 & 3 \\
\hline $\begin{array}{l}\text { Goal } \\
\text { orientation }\end{array}$ & 1. Intrinsic & 4.09 & .68 & - & & \\
\hline \multirow[t]{2}{*}{$\begin{array}{l}\text { Deep } \\
\text { approach }\end{array}$} & $\begin{array}{l}\text { 2. Deep } \\
\text { strategy }\end{array}$ & 3.64 & .78 & $.528^{* *}$ & - & \\
\hline & $\begin{array}{l}\text { 3. Meta } \\
\text {-cognitive }\end{array}$ & 3.69 & .74 & $.546^{* *}$ & $.804^{* *}$ & - \\
\hline
\end{tabular}

\section{B. The impact of intrinsic goal orientation on deep learning approach}


Students' intrinsic goal orientation was used in a simple linear regression analysis to predict students' deep learning approach through deep and meta-cognitive learning strategies. To predict deep learning strategies, the model was statistically significant $(F(1,203)=78.299, p<.001)$ and accounted for approximately $28 \%\left(\mathrm{R}^{2}=.278\right)$ of the variance of deep learning strategies. Intrinsic goal orientation, therefore, positively predicted deep strategies $[\beta=.53, \mathrm{t}=8.849, \quad p<.001]$. Furthermore, to predict meta-cognitive learning strategies, a significant regression equation was found $(F(1,203)=86.161$, $p<.001)$, with an $\mathrm{R}^{2}$ of .298 . Intrinsic goal orientation, therefore, further predicted meta-cognitive learning strategies positively $[\beta=.54, \mathrm{t}=9.282, p<.001]$.

\section{Disparities of intrinsic goal orientation and deep learning approach}

Concerning gender differences, independent samples $t$-test was conducted and the results reveal that there was a significant gender difference on intrinsic goal orientation; male students had higher scores than their female counterparts $(p<0.05)$. No significant differences were observed on deep and meta-cognitive learning strategies (see Table 2).

\section{TABLE 2. GENDER T-TEST RESULTS AND THEIR P VALUES $(\mathrm{n}=205)$}

\begin{tabular}{|c|c|c|c|c|c|c|c|}
\hline \multicolumn{2}{|l|}{ Variable } & \multicolumn{2}{|c|}{ Male } & \multicolumn{2}{|c|}{ Female } & \multirow[t]{2}{*}{$t(203)$} & \multirow[t]{2}{*}{$\bar{p}$} \\
\hline \multirow{4}{*}{$\begin{array}{l}\text { Goal } \\
\text { orientation } \\
\text { Deep } \\
\text { approach }\end{array}$} & & Mean & $\mathrm{SD}$ & Mean & SD & & \\
\hline & 1. Intrinsic & 4.149 & .754 & 3.928 & .737 & $2.076^{*}$ & .039 \\
\hline & $\begin{array}{l}\text { 2. Deep } \\
\text { strategy }\end{array}$ & 3.717 & .776 & 3.553 & .767 & 1.488 & .138 \\
\hline & $\begin{array}{l}\text { 3. Meta- } \\
\text { cognitive }\end{array}$ & 3.692 & .714 & 3.513 & .680 & 1.794 & .074 \\
\hline
\end{tabular}

A one-way analysis of variance (ANOVA) was performed to determine the differences based on students' affiliation to a particular program (MBBS, PHARM, MLS and PHYSIO). Results reveal that there were no statistically significant differences between the four group means on all the three constructs tested in this study $(p<.05)$ : intrinsic goal orientation $[F(3,201)=1.58, p=.196]$; deep strategies $[F(3$, $201)=.38, p=.769]$; and meta-cognitive strategies $[F(3,201)$ $=.72, p=.543]$.

\section{DISCUSSION}

The primary goal of this study was to analyze whether intrinsic goal orientation would predict deep approach to learning. Findings clearly reveal that intrinsic goal orientation predicted both deep and meta-cognitive learning strategies, which represented deep learning approach in this study. The results, therefore, suggest that students who were intrinsically motivated focused their attention on the underlying meanings and the successful applications of the content learnt. In other words, students who focused on internal factors such as mastering and understanding the materials used deep information processing strategies. This further suggests that intrinsically goal oriented students were more likely to plan, organize, monitor and evaluate their studies than their fellow counterparts. These results agree with what Dolmans et al. [5] found; students' intrinsic motivation was found to enhance deep learning among college students. In higher education, especially in medical schooling, educating students to become life-long learners who can effectively apply the theoretical concepts to their professional contexts is an important aspect. However, it has been discovered that for students to effectively become versatile experts in their own fields, they need to adopt deep learning approach, and for them to achieve this best trait of a student, they need to be intrinsically motivated. Therefore, it is crucial for students to first be intrinsically motivated and adopt intrinsic goal orientation, for them to effectively use deep learning approach during their studies.

Students' intrinsic goal orientation and deep approach to learning are important factors to be taken into consideration especially if educators aim at enhancing students' knowledge, attitude and psychomotor abilities. As previously stated, depending on individual and the learning environmental factors, intrinsic and extrinsic goal orientations can coexist in an individual at different times $[11,12,18]$. At the same time, students' orientation to studying and the context of learning within individual courses may influence students to adopt both deep and surface approaches in different situations during their studies $[21,22]$. These two dichotomies are not mutually exclusive; it is possible for the two in each construct to coexist. Therefore, it is certain to conclude that there are some individual and especially teaching environmental factors that affect students to dominantly choose one approach, in this case either being more of intrinsic goal orientation using deep learning approach or being more of extrinsic goal orientation using shallow learning approach. There is a great need therefore, to foster and stimulate the development of effective goal orientation and approaches to learning among students in colleges.

As research indicates, apart from individual factors, there are several factors in the learning environment that affect students' goal orientation [11,12,18] and approaches to learning $[4,5,21]$. Depending on how the teaching and assessment activities award either deep or surface learning approaches, students' orientation to studying may also change. Briggs and Tang [21] argue that teacher-related factors such as teaching piecemeal content, assessing mainly for memorizing facts, and providing insufficient time by overloading students can influence students towards adopting a surface approach to learning. In line with this argument, Dolmans et al. [5] argue that a highly perceived workload and assessment that is perceived as not satisfying deep learning are postulated to augment surface learning. As reported by a number of studies conducted in medical field, [1,31,32,33], students already perceive medical subjects especially Anatomy as overloaded and difficult to understand. The perceived overload, coupled with the assessment methods commonly done in medical field, students adopt rote learning as their principal learning strategy to cope with their studies [27].

Regarding disparities of intrinsic goal orientation and deep learning approach experiences among students, the study revealed that there was gender significant difference on intrinsic goal orientation; male students were more intrinsically goal oriented that their female counterparts. This 
finding support other research findings in sciences, especially in medical education, which indicate that male students are more self-efficacious and therefore become more motivated to study [12,34,35]. As Ngwira et al. [1] argue, this gender difference in intrinsic goal orientation suggests that there are some factors that enhance male students' motivation, or harm female students' motivation when it comes to learning sciences. This could be due to lack of female role models in sciences and the gender-linked stereotypes. In Malawi, this gender gap toward learning science exists as early as primary school [1]. Boys' performance outweighs that of girls in science subjects like Mathematics and as a result, girls believe they are not good at sciences, even if they are, and this weakens their motivation to learn. Conversely, boys become self-efficacious in their science learning and according to the recent research [1], they enjoy learning medical subjects more than girls do, and this enjoyment facilitates their learning by enhancing their intrinsic motivation. Educators in the medical field need to foster and stimulate the development of intrinsic goal orientation in female students, and this will enhance deep approach learning which bolsters effective learning.

Interestingly, the results on deep learning approach experiences among students indicate insignificant differences. This means that as regards to gender and program of study, all students employed deep learning approach in terms of deep and meta-cognitive learning strategies in the same way. The insignificant results, however, are not in line with the study's hypothesis which was based on other research findings in sciences [12,36], and the goal orientation model [10]. It was expected that students who were intrinsically motivated would adopt deep learning approach more than their fellow counterparts. According to the current results on intrinsic goal orientation, male students would have displayed higher levels of deep approach than female students. Even in medical education, studies [34,35] report that male students are more self-efficacious and therefore become more motivated to study and are more likely to use deep information processing strategies than female students. However, in support of the current results, some few studies found similar results where there were no significant differences between male and female students despite their different perceived self-efficacy which is one of the motivational components [1,28,37]. As Artino et al. [38] argue, the findings are typical of first year medical and allied students who are trying many ways of dealing with the perceived difficult and overloaded basic medical courses.

Thus, the present study supports that intrinsic motivation enhances students' learning. The findings imply that intrinsic goal orientation plays a significant role on medical and allied students' deep learning approach. It is therefore paramount for educators to cultivate intrinsic goal orientation in students, which eventually bolsters deep learning approach them. While educators cannot influence the orientation to learning that students initially bring to their studies, they are able to manipulate the learning context, providing an opportunity to influence the approach students would adopt [22]. On this regard, through a very conducive learning environment, educators can influence students to adopt the right goal orientation and learning approach. The learning environment, in this case, includes both the nature of the course and the teaching/assessing within the course. The best approach that would enhance intrinsic motivation and deep learning approach is by engaging students in an active learning. According to Briggs \& Tang [21], teaching factors such as teaching to bring out the underlying structure of the subject matter, teaching to get active responses rather than passive responses from students, engaging students in the lesson, assessing for understanding of underlying structure rather than facts only, creating a positive working atmosphere, and emphasizing depth rather than breadth of learning, would influence students towards a deep approach to learning.

Having information on students' goal orientations and learning approaches is vital for the development of teaching and learning approaches. The principal aim for students should be to understand new concepts, relate them with prior knowledge and experiences, and be able to apply the knowledge in their professional contexts. Especially in the medical field, knowledge gained at school need to be applied effectively, as these professionals deal directly with the life of people. According to findings from other researches, deep learning approach helps the learner to understand new information, relate them with prior knowledge, and apply the knowledge in their professional contexts [4,21,22,23]. Studies have revealed that the employment of PBL allows students to attain skills on problem solving, apply their own knowledge, and obtain new information while solving these problems $[4,5,7,8]$. In another words, PBL teaching approach entails engaging students in an active learning and this is the most important way to even activate passive students, as long as educators provide a conducive learning environment.

\section{A. Conclusions, limitations and further research}

The present study aimed at investigating the role of intrinsic goal orientation on students' deep learning approach in the learning context of medical and allied health students at College of Medicine in Malawi. This is an essential field of research in medical education as previous studies have reported positive effects of these constructs in education $[9,16]$. This paper makes two major contributions to the literature. First, based on the findings, the study has affirmed the role intrinsic goal orientation plays on deep approach to learning. The paper has highlighted the importance of each concept in education and the need to foster such orientations in students. Second, based on the different models, findings and recommendations derived from the goal orientation and learning approach previous research, the paper has provided possible suggestions on how educators, especially in medical field, can foster and stimulate such orientations to learning. Educators can influence students' goal orientations and learning approaches through the manipulation of the learning contexts such as teaching approaches, workloads and assessments.

The findings are, however, subject to some limitations. First, this was a cross-sectional study and therefore, it has not given information on changes in goal orientation and learning approach among students over time. The study's target population was first year students and as they proceed with their studies, their orientation towards goal orientations and learning approaches would change. Longitudinal studies, therefore, are needed to investigate changes in both constructs over a certain period of time, and whether such changes would 
affect their relationship. Second, due to the large number of potential participants in the study population, medical education, the study focused only on first year students. Due to its sample uniqueness, results might not simply be generalized beyond this specific target population. This is because students' goal orientation and approaches to learning might not be the same at different levels and in different contexts since these psychological concepts are bound to be affected by the learning environment as well. Consequently, medical researchers need to conduct systematic studies focusing on how students in different medical schools, different programs and different year groups adopt intrinsic goal orientation and deep approach to learning. Finally, the study did not include the relationship between each study construct with students' performance (achievement). The study linked intrinsic goal orientation and deep learning approach with academic performance based on previous findings. Future research especially in medical field would do well to include an investigation of the relationship between intrinsic goal orientation and academic performance, and between deep learning approach and academic performance.

\section{REFERENCES}

[1] F.F. Ngwira, G. Gu, H.W.T. Mapoma, and W. Kondowe, "The role of academic emotions on medical students' self-regulated learning strategies," Journal of Contemporary Medical Education, vol. 5(1), pp. 23-30, 2017. doi: 10.5455/jcme.20170412124640

[2] L.H. Tembo, and F.F. Ngwira, "The impact of self-efficacy beliefs on learning strategies: towards learning human anatomy at College of Medicine in Malawi," Journal of Contemporary Medical Education, vol. 4, pp. 1-7, 2016. doi: $10.5455 /$ jcme. 20160603033340

[3] L. Samarakoon, T. Fernando, C. Rodrigo, and S. Rajapakse, "Learning styles and approaches to learning among medical undergraduates and postgraduates," BMC Medical Education, vol. 13(42), pp. 1-6, 2013. doi:10.1186/1472-6920-13-42

[4] E. Gurpinar, E. Kulac, C. Tetik, I. Akdogan, and S. Mamakli, "Do learning approaches of medical students affect their satisfaction with problem-based learning?" Adv Physiol Educ vol. 37, pp. 85-88, 2013. doi:10.1152/advan.00119.2012.

[5] D.H.J.M. Dolmans, S.M.M. Loyens, H. Marcq, and D. Gijbels, "Deep and surface learning in problem-based learning: a review of the literature," Adv in Health Sci Educ, 2015. doi: 10.1007/s10459-0159645-6

[6] G.C. Koh, H.E. Khoo, M.L. Wong, and D. Koh, "The effects of problem-based learning during medical school on physician competency: a systematic review," CMAJ, vol. 178(1), pp. 34-41, 2008.

[7] H. Barrows, and R. Tamblyn, Problem-based learning: an approach to medical education. New York, NY: Springer Pub Co, 1980.

[8] M. van Den Hurk, "The relation between self-regulated strategies and individual study time, prepared participation and achievement in a problem-based curriculum," Active Learning in Higher Education, vol. 7, pp. 155-169, 2006.

[9] D.L. McCollum, and L.T. Kajs, "Applying Goal Orientation Theory in an Exploration of Student Motivations in the Domain of Educational Leadership," Educational Research Quarterly, vol. 31(1), pp. 45-59, 2007.

[10] P.R. Pintrich, and D.H. Schunk, Motivation in education. Englewood Cliffs, NJ: Prentice Hall, 1996.

[11] A.R. Mattern, "College Students' Goal Orientations and Achievement," International Journal of Teaching and Learning in Higher Education, vol. 17(1), pp. 27-32, 2005.

[12] P. R. Pintrich, "The role of goal orientation in self-regulated learning," in Handbook of self-regulation, M. Boekaerts, P. R. Pintrich, and M. Zeidner, Eds. San Diego, CA: Academic, 2000, pp. 451-502.
[13] P. R. Pintrich, and T. Garcia, "Student goal orientation and selfregulation in the college classroom," in Advances in motivation and achievement, vol. 7, M. Maehr and P. R. Pintrich, Eds. Greenwhich, CT: JAI, 1991, pp. 371-403.

[14] P. R. Pintrich, (1989). The dynamic interplay of student motivation and cognition in the college classroom," in Advances in motivation and achievement: motivation enhancing environments, vol. 6, C. Ames, and M. Maehr, Eds. Greenwich, CT: JAI, 1989, pp. 117-160.

[15] K.P. Murphy, and P. Alexander, "A motivated exploration of motivation terminology," Contemporary Educational Psychology, vol. 25, pp. 3-53, 2000.

[16] C.A. Wolters, S.L. Yu, and P.R. Pintrich, "The relation between goal orientation and students' motivational beliefs and self-regulated learning," Learning and Individual Differences, vol. 8(3), pp. 211-236, 1996.

[17] J.M. Froiland, E. Oros, L. Smith, and T. Hirchert, "Intrinsic Motivation to Learn: The Nexus between Psychological Health and Academic Success," Contemporary School Psychology, vol. 16, pp. 91-100, 2012.

[18] M.S. Lemos, and L. Veríssimo, "The relationships between intrinsic motivation, extrinsic motivation, and achievement, along elementary school," Social and Behavioral Sciences, vol. 112, pp. 930-938, 2014. doi: 10.1016/j.sbspro.2014.01.1251

[19] F. Marton, and R. Saljo, "On qualitative differences in learning: I outcome and process," British Journal of Educational Psychology, vol. 46 (1), pp. 4-11, 1976a.

[20] F. Marton, and R. Saljo, "On qualitative differences in learning: II outcome as a function of the learner's conception of the task," British Journal of Educational Psychology, vol. 46(2), pp. 115-127, 1976b.

[21] J.B. Briggs, and C. Tang, Teaching for quality learning at university, 3rd ed., Berkshire: Open University Press, 2007.

[22] L. English, P. Luckett, and R. Mladenovic, "Encouraging a deep approach to learning through curriculum design, Accounting Education," An International Journal, vol. 13(4), pp. 461-488, 2004. doi: 10.1080/0963928042000306828

[23] D. Gijbels, V. Donche, J.T.E. Richardson, and J.D. Vermunt, "Learning patterns in higher education: dimensions and research perspectives. London: Routledge, 2014.

[24] P. Howie, and R. Bagnall, "A critique of the deep and surface approaches to learning model," Teaching in Higher Education, pp. 1-12, 2012. doi:10.1080/13562517.2012.733689

[25] T.F.N. Laird, "Measuring deep approaches to learning using the national survey of student engagement," Paper presented at the Annual Meeting of the Association for Institutional Research, May 14 - May 18, Chicago, IL. 2005.

[26] V. Beattie, B. Collins, and B. McInnes, "Deep and surface learning: a simple or simplistic dichotomy?" Accounting Education: An International Journal, vol. 6(1), pp. 1-12, 1997. doi: $10.1080 / 096392897331587$

[27] M. Varunki, N. Katajavuori, and L. Postareff, "First year students' approaches to learning, and factors related to change or stability in their deep approach during a pharmacy course," Studies in Higher Education, 2015. doi: 10.1080/03075079.2015.1049140

[28] K.M. Stegers-Jager, J. Cohen-Schotanus, and A.P. Themmen, "Motivation, learning strategies, participation and medical school performance," Med Educ, vol. 46, pp. 678-688, 2012.

[29] R.A. Woodhouse, M.D. Delva, A.F. Hadwin, R.V. Birtwhistle, J.R. Kirby, and C. Knapper, "Medical students' learning strategies in problem-based learning and traditional courses," in Advances in Medical Education, A.J.J.A. Scherpbier et al., Eds, Netherlands, Kluwer: Academic Publishers, 1997, pp. 632-634.

[30] P.R. Pintrich, D.A.F. Smith, T. García, and W.J. McKeachie, A manual for the use of the Motivated Strategies for Learning Questionnaire MSLQ). Ann Arbor: University of Michigan, National Center for Research to Improve Postsecondary Teaching and Learning, 1991.

[31] A. Alam, "How do medical students in their clinical years perceive basic sciences courses at King Saud University?" Annals of Saudi Medicine, vol. 31(1), pp. 58-61, 2011. 
[32] S. Gupta, A.K. Gupta, M. Verma, H. Kuar, A. Kaur, and K. Singh, "The attitudes and perceptions of medical students towards basic science subjects during their clinical years: a cross-sectional survey," International Journal of Applied Basic Medical Research, vol. 4(1), pp. 16-19, 2014.

[33] M.I. Ebomoyi, and F.D. Agoreyo, "Preclinical students' perceptions of their courses and preclinical specialty choice," Journal of Medicine and Biomedical Research, vol. 6 (1 \& 2), pp. 47-58, 2007.

[34] A.S, Khan, Z. Cansever, U.Z. Avsar, and H. Acemoglu, "Perceived selfefficacy and academic performance of medical students at Ataturk University, Turkey," J Coll Phys Surg Pak, vol. 23(7), pp. 495-498, 2013.

[35] L. Ramos-Sanchez, L. Nichols, "Self-efficacy of first-generation and non-first-generation college students: the relationship with academic performance and college adjustment," J Coll Couns., vol. 10, pp. 6-18, 2007.

[36] A. Bandura, "Exercise of personal agency through the self-efficacy mechanism," in Self-efficacy: thought control of action, R. Schwarzer, ed., Washington, DC: Hemisphere, 1992, pp. 3-38.

[37] D.L. Witt-Rose, "Student self-efficacy in college science: an investigation of gender, age and academic achievement," Dissertation, University of Wisconsin-Stout Menomonie, 2003.

[38] A.R. Artino, J.S. La Rochelle, and S.J. Durning, "Second-year medical students' motivational beliefs, emotions, and achievement," Med Educ vol. 44 pp. 1203-1212, 2010. 